\title{
HERDING IN STYLE ALLOCATIONS
}

\author{
Laura ANDREU ${ }^{1}$, Cristina ORTIZ ${ }^{2}$, José Luis SARTO \\ Department of Accounting and Finance, Faculty of Economics and Business Studies, \\ University of Zaragoza, Gran Via 2, 50.005, Spain \\ E-mails: ${ }^{1}$ landreu@unizar.es (correspondingauthor); ${ }^{2}$ cortiz@unizar.es; $3 j$ jlsarto@unizar.es
}

Received 10 October 2011; accepted 27 November 2012

\begin{abstract}
The study examines herding behavior in the strategic allocations of UK pension plans. The results show that UK pension managers are involved in cross-sectional herd behavior. The study also examines herding from a quantitative perspective considering the number of managers changing their style allocations and from an intertemporal perspective to examine the tendency of UK pension plans to imitate others over time. Finally, a robustness analysis considering passive style portfolios is applied to eliminate artificial herding. Hence, the paper contributes to the literature by analyzing herding at strategic allocations instead of at the individual stock level as well as by improving the methodology used to capture the herding phenomenon. The results have practical implications to design managers' compensation schemes due to their influence on manager behavior.
\end{abstract}

Keywords: herding behavior, portfolio managers, style allocations, intertemporal imitation, compensation schemes, pension plans.

JEL Classification: G23.

\section{Introduction}

The increasing importance of institutional managers for stock markets has encouraged research on the influence their trading exerts on asset prices. This interest is due to the belief that institutional herding behavior may have consequences on the stability of financial markets ${ }^{1}$. Theoretical models have suggested that the most important explanations are the institutional feedback trading (Barberis, Shleifer 2003), career concerns (Scharfstein, Stein 1990; Trueman 1994), informational cascades (Banerjee 1992; Bikhchandani et al. 1992), and the existence of fads and correlated signals (Hirshleifer et al. 1994). Consequently, there are three central questions in the herding literature. Do institutions herd? Why do institutions herd? and Does institutional herding destabilize prices?

Although empirical literature has traditionally focused on testing institutional herding in individual securities, the proposed explanations for institutional herding hold at least equally well at the industry level (Choi, Sias 2009) and at the investment style

\footnotetext{
${ }^{1}$ Financial literature defines "herding" as the simultaneous trend of managers to buy or sell a particular stock in a given time period relative to what could be expected if managers trade independently.
} 
level proposed in this paper. Therefore, the primary goal of the paper is to address the fundamental question: Do institutional pension managers herd across style allocations?

The majority of the studies have analyzed the existence of herding of US investment funds. By using the measure proposed by Lakonishok et al. (1992), these studies show that the actual extent of herding by institutional managers is modest when analyzing portfolio holdings (see, Grinblatt et al. 1995; Wermers 1999; Borensztein, Gelos 2000). Some exceptions that analyze pension managers' behavior are Lakonishok et al. (1992) and Jones et al. (1999). The pioneering study of Lakonishok et al. (1992) develops a herding metric (LSV henceforth) to investigate the holdings of US pension funds, concluding that herding in large stocks is modest. Jones et al. (1999) report that US pension managers act as feedback traders, especially in small stocks with a high past performance. Herding behavior has also been analyzed in other developed markets such as the UK. Specifically, De Bondt and Forbes (1999) analyze herding in analysts' forecasts. Meanwhile, Hwang and Salmon (2001) propose a herding measure based on the cross-sectional dispersion of factor sensitivity of assets, finding that herding towards the market portfolio arises during relatively quiet periods rather than when markets are under stress. Later, Wylie (2005) analyzes herding using the LSV measure on the portfolio holdings of $268 \mathrm{UK}$ equity mutual funds. The study shows that the herding level is higher for the smallest stocks, as found by Lakonishok et al. (1992) and Wermers (1999). On the other hand, other recent studies have focused their attention on new methods to detect the existence of herding (see, Frey et al. 2014) or how fundamental and macroeconomic information impact on this phenomenon (see, Galariotis et al. 2015). Additionally, other recent papers have answered the other questions in the herding literature. Specifically, Holmes et al. (2013) examine why herding takes places and whether such behavior is intentional or spurious while Shu-Fan Hsieh (2013) focuses on the impact of herding on stock returns.

This paper investigates herding behavior in the strategic allocations of UK personal pension plans in the period 2000-2007 since the investment policy is one of the most relevant decisions of portfolio management, especially when analyzing pension plans (see, Ibbotson, Kaplan 2000). The study of strategic asset allocations can be tackled using both portfolio holdings and return data. Both analyses have advantages and disadvantages. On the one hand, return data is apparently less informative than holdings since we have to infer trades from estimating a regression of pension returns on benchmark returns. However, return data is published with higher frequency which makes easier the detection of the behavioral patterns followed by managers. On the other hand, portfolio holdings in reporting dates can be biased due to practices such as window dressing. For that reason and given that portfolio holdings of UK pension plans are not publicly available with high frequency, we analyze the style herding phenomenon through the return-based style analysis.

Initially, the traditional LSV measure has been applied, finding levels of herding higher than those previously observed in studies using portfolio holdings. However, the traditional measure may lead to an artificial evidence of herding since the variations in style 
exposures can be due not only to managers' intention. For that reason, we propose the comparison of the results obtained to those that will be shown by portfolios that maintain their investment style along time ("passive style portfolios"). This analysis leads to a lower herding level since the artificial herding is eliminated.

After that, we explore whether these results are meaningful given the biases and limitations that some authors attribute to the traditional LSV metric. We propose an alternative approach to capture herding in which the probability of increasing and decreasing a style exposure considers the magnitude of the previous exposure. Finally, we also examine the level of herding through the use of the amount ratio and a time-series analysis. The findings of these analyses are consistent with those obtained by the traditional metric, even when controlling the existence of artificial herding with the robustness analysis of passive style portfolios.

Our paper contributes to several strands of the literature. First, we contribute to the growing "style investing" literature (see, e.g. Teo, Woo 2004; Barberis et al. 2005; Choi, Sias 2009) by analyzing herding at the strategic allocation level instead of at the individual security level. Second, our paper is related to previous studies on "style investing". However, prior literature have focused on equity markets and have used market capitalization and book-to-market ratios (Teo, Woo 2004) or industry classifications (Choi, Sias 2009) as their main style definitions while this paper pays attention to strategic style allocations and therefore also includes the bond and cash style. As far as we know, this study is the first attempt to formally analyze the herding behavior of UK personal pension plans through the use of strategic allocations. Finally, this study also contributes to the literature by improving the methodology used to capture institutional herding behavior. Specifically, we firstly analyze this behavior through the traditional method of Lakonishok et al. (1992) and then we propose three complementary approaches: (1) Alternative approach that calculates an accurate value of the probability of increasing a style exposure taking into account the magnitude of the previous exposure, (2) Quantitative perspective and (3) Time-series perspective.

Our results have important implications for management companies given the influence of compensation schemes and career concerns on manager behavior. Therefore, our study would help management companies to design their compensation schemes. Finally, our analysis of UK pension plans is also justified by the importance of the British market with respect to the rest of the markets in general and to the European industry in particular.

The remainder of the paper is as follows: Section 1 introduces our database. Section 2 explains the methodology used for measuring herding behavior in strategic style allocations. Section 3 presents the empirical results obtained by applying the traditional herding measure. Section 4 includes the additional analyses proposed to solve some of its biases and shortcomings. Finally, conclusions are summarized. 


\section{Data}

This paper analyzes herding in strategic style allocations of UK personal pension plans categorized as balanced according to their investment vocation. We analyze the style allocation of these defined contribution pension schemes using monthly return from June 2000 to December 2007. Initially, we have returns of 260 UK balanced pension plans. However, the requirement of at least 36 observations to estimate robust parameters leads to a final sample of 193 pension plans. The dataset is free of survivorship bias, a relevant feature because the consideration of only those funds that survived could create an illusion of herding (Wylie 2005). This information was obtained from Micropal. Our analysis of the strategic allocations of UK balanced personal pension plans forces us to collect monthly returns of a series of benchmarks representative of the main holdings of these portfolios. We collect equity, fixed-income and cash indexes given the characteristics of balanced portfolios. Therefore, the style model proposed is not limited to equity factors such as size and book-to-market indexes as in previous research examining style investing. This information was obtained from Morgan Stanley Capital International-Barra (MSCI-Barra) in the case of equity benchmarks and from the Bank of England in the case of fixed-income and cash indexes.

Table 1 provides descriptive statistics of the monthly returns and volatility (standard deviation) of the UK personal pension plans analyzed along with the information of the whole spectrum of benchmarks initially considered.

Table 1. Descriptive statistics

\begin{tabular}{lccccc}
\hline \multicolumn{1}{c}{ Pension plans } & Mean & Median & $\begin{array}{c}\text { 25th } \\
\text { percentile }\end{array}$ & $\begin{array}{c}75 \text { th } \\
\text { percentile }\end{array}$ & $\begin{array}{c}\text { Standard } \\
\text { deviation }\end{array}$ \\
\hline Equally-weighted portfolio & 0.0033 & 0.0104 & -0.0115 & 0.0227 & 0.0302 \\
\hline Benchmarks & & & & & \\
\hline MSCI UK & 0.0038 & 0.0106 & -0.0137 & 0.0283 & 0.0359 \\
\hline MSCI Europe & 0.0044 & 0.0099 & -0.0168 & 0.0326 & 0.0440 \\
\hline MSCI USA & -0.0006 & 0.0052 & -0.0214 & 0.0254 & 0.0452 \\
\hline MSCI Japan & -0.0013 & -0.0008 & -0.0343 & 0.0305 & 0.0520 \\
\hline MSCI World Index & 0.0014 & 0.0092 & -0.0214 & 0.0303 & 0.0419 \\
\hline 10-year Fixed-Income & 0.0038 & 0.0038 & 0.0036 & 0.0040 & 0.0003 \\
\hline 5-year fixed-income & 0.0039 & 0.0038 & 0.0036 & 0.0041 & 0.0004 \\
\hline 3-year fixed-income & 0.0038 & 0.0038 & 0.0035 & 0.0041 & 0.0004 \\
\hline 1-year fixed-income & 0.0037 & 0.0037 & 0.0034 & 0.0041 & 0.0005 \\
\hline 1-month treasury bill repos & 0.0038 & 0.0037 & 0.0032 & 0.0042 & 0.0006 \\
\hline
\end{tabular}

Notes: The table shows descriptive statistics for our sample of UK balanced personal pension plans (equally-weighted portfolio) and for the benchmarks initially proposed. The data is reported in monthly terms considering the entire period of analysis June 2000 - December 2007. 


\section{Methods}

\subsection{The traditional LSV herding measure}

The main aim of the paper is to determine whether UK pension plan managers are engaged in herding behavior when they decide their investment allocations. For that reason, we firstly use the well-known LSV herding measure developed by Lakonishok et al. (1992), given that its generalized application makes easier the international comparability of the empirical findings.

According to this measure, herding is the simultaneous trend of managers to buy or sell a particular stock in a given period relative to what could be expected if managers trade independently. In our context of style allocations, herding is identified as the tendency of pension managers to change a specific allocation in the same direction (increase or decrease) in a given period. In other words, there is herding behavior when the proportion of managers who increase (reduce) a style allocation in a specific benchmark is above the expected proportion under the null hypothesis of independent management decisions. Therefore, positive and statistically significant values of the metric will provide evidence of herding behavior. The LSV measure defines herding for a given style $j$ in a given period $t, H(j, t)$ as follows:

$$
H(j, t)=|p(j, t)-p(t)|-A F(j, t),
$$

where:

$$
\begin{gathered}
p(j, t)=\frac{B(j, t)}{B(j, t)+S(j, t)}, \\
p(t)=\frac{\sum_{j=1}^{k} B(j, t)}{\sum_{j=1}^{k} B(j, t)+\sum_{j=1}^{k} S(j, t)}, \\
A F(j, t)=E[|p(j, t)-p(t)|],
\end{gathered}
$$

where $B(j, t)$ and $S(j, t)$ represent the number of managers who increase and decrease their exposure in benchmark $j$ over period $t$ (net buyers and net sellers); these expressions follow a binomial distribution with probability $p(t) ; p(j, t)$ is the percentage of increasing managers in benchmark $j$ in period $t$; and $p(t)$ is the expected proportion of managers increasing their exposure in that period relative to the number of active managers aggregated across all benchmarks. $A F(j, t)$ is the adjustment factor calculated under the assumption that trades follow a binomial distribution, with $B(j, t)$ and $S(j, t)$ as success and failure outcomes.

\subsection{The return-based style analysis}

Our analysis requires the calculation of style allocations of UK pension plans and to do so, we use the return-based style analysis (RBSA) proposed by Sharpe (1992). This methodology has become a standard technique for inferring a fund's investment style because it only requires return as input data. Concretely, the style analysis is a con- 
strained regression that uses a weighted combination of market indexes to replicate, as closely as possible, the historical return pattern of a portfolio. Therefore, the analysis consists of a quadratic optimization of a style model to obtain the average sensitivity of the portfolio returns to different benchmarks. As a result, the best explanation for the return of a given portfolio is given by the weights that minimize the residual variance of the model subject to two constraints. First, the weights are non-negative since short sales are not allowed (positivity constraint). Second, the weights sum to 1 since all the portfolio must be invested (portfolio constraint).

In this sense, to measure the performance of common stock funds, Elton et al. (1996) recommend a four-index model that includes the S\&P 500 index, a size index, a growth versus value index, and a bond index. With regard to fixed-income benchmarks, Sharpe (1992) uses both a government bond index and corporate bond indexes. Similarly, Fama and French (1993) illustrate that a bond model should include factors related to maturity risk and default risk.

Table 2 reports the correlations for the benchmarks initially considered to collect the main groups of assets in which UK balanced pension plans invest. We have considered several equity benchmarks to account for the most important investment markets (UK, Europe, US, Japan and the World) as well as fixed-income benchmarks to account for different maturities (10-year, 5-year, 3-year and 1-year period) and a benchmark representative of cash (1-month Treasury Bill Repos).

The high value of Pearson's coefficients between the different equity benchmarks analyzed leads us to test the correlation between the returns of UK pension plans and these indexes to determine the equity benchmark of the model. Based on these results, we decide to use the MSCI World index, given that this benchmark shows the highest correlation to UK pension plan returns. In addition to MSCI World large + mid cap index

Table 2. Correlation coefficients

\begin{tabular}{|c|c|c|c|c|c|c|c|c|c|c|}
\hline & $\begin{array}{c}\text { MSCI } \\
\text { UK }\end{array}$ & $\begin{array}{c}\text { MSCI } \\
\text { Europe }\end{array}$ & $\begin{array}{c}\text { MSCI } \\
\text { US }\end{array}$ & $\begin{array}{c}\text { MSCI } \\
\text { Japan }\end{array}$ & $\begin{array}{l}\text { MSCI } \\
\text { World }\end{array}$ & 10-y FI & 5-y FI & 3-y FI & 1-y FI & Repos \\
\hline MSCI UK & 1 & 0.955 & 0.832 & 0.447 & 0.899 & -0.135 & -0.119 & -0.088 & -0.028 & -0.028 \\
\hline MSCI Europe & & 1 & 0.859 & 0.465 & 0.932 & -0.166 & -0.142 & -0.109 & -0.043 & -0.041 \\
\hline MSCI US & & & 1 & 0.522 & 0.974 & -0.133 & -0.119 & -0.092 & -0.035 & -0.018 \\
\hline MSCI Japan & & & & 1 & 0.615 & -0.233 & -0.239 & -0.211 & -0.156 & -0.160 \\
\hline MSCI World & & & & & 1 & -0.172 & -0.155 & -0.123 & -0.055 & -0.043 \\
\hline 10-y FI & & & & & & 1 & 0.905 & 0.808 & 0.585 & 0.332 \\
\hline 5-y FI & & & & & & & 1 & 0.980 & 0.845 & 0.617 \\
\hline 3-y FI & & & & & & & & 1 & 0.926 & 0.724 \\
\hline $1-\mathrm{y} \mathrm{FI}$ & & & & & & & & & 1 & 0.911 \\
\hline Repos & & & & & & & & & & 1 \\
\hline
\end{tabular}

Notes: The table shows the Pearson's correlation coefficients among the benchmarks. 
we also include the MSCI World small index to account for the different behavior of small stocks. On the other hand, we choose the 10-year fixed-income index as representative of the bond investment since this index shows the lowest correlation to cash (1-month UK Treasury Bill Repos). Therefore, based on Table 2, and bearing in mind the requirements of exhaustivity, exclusivity and independence of the benchmarks, we define the following style model:

$$
\begin{aligned}
& \operatorname{Min} \sum_{t=1}^{T}\left(\varepsilon_{t}^{p}\right)^{2}=\operatorname{Min} \sum_{t=1}^{T} \mid R_{t}^{p}-\left(\beta_{0}^{p}+\beta_{1}^{p} R_{M S C I W o r l d L \arg e+\text { Mid }, t}+\right. \\
& \left.\beta_{2}^{p} R_{M S C I W o r l d S m a l l, t}+\beta_{3}^{p} R_{10 y \text { PublicBonds }, t}+\beta_{4}^{p} R_{\operatorname{Re} p o s, t}\right)\left.\right|^{2}, \\
\text { subject to } & \sum_{j=1}^{4} \beta_{j}^{p}=1 \quad 0 \leq \beta_{j}^{p} \leq 1,
\end{aligned}
$$

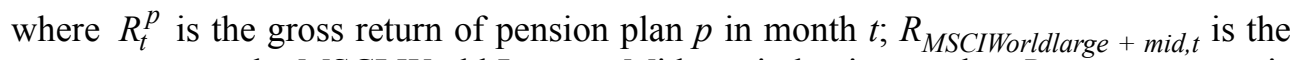
gross return on the MSCI World Large + Mid cap index in month $t, R_{\text {MSCIWorld Small, } t}$ is the gross return on the MSCI World Small cap index in month $t, R_{10 y \text { PublicBond,t }}$ is the gross return on the 10-year UK Public Debt index in month $t$ and $R_{\text {Repos, } t}$ is the gross return of 1-month UK Treasury Bill Repos in month $t, \beta_{j}^{p}$ is the style weight of the basic asset class $j$ (where $j=1$ to 4 ) of pension plan $p, \beta_{0}^{p}$ is the part of the return that active management adds to the merely passive tracking of the benchmark portfolio and $\varepsilon_{t}^{p}$ is the residual return not captured by the model.

\subsection{Application of the traditional LSV herding measure to style allocations}

Next, the study focuses on the evolution of the strategic allocations over time. We estimate the style weights of each pension plan $p$ considering 35-month and 36-month rolling windows.

Given the portfolio constraint of Sharpe's (1992) model, the comparison of the weights allocated by each portfolio in two consecutive rolling windows allows us to investigate whether managers are increasing or decreasing their exposure to a certain benchmark. Although the LSV measure gauges herding without regard to the direction of the movements, we divide this metric into buying herding and selling herding. We thus define a buying or selling pension plan $p$ in a strategic style $j$ if:

$$
\left.\begin{array}{l}
\beta_{j, 36}^{p}>\beta_{j, 35}^{p} \\
\beta_{j, 36}^{p}<\beta_{j, 35}^{p}
\end{array}\right\} \quad \begin{aligned}
& \text { (buying), } \\
& \text { (selling), }
\end{aligned}
$$

where $\beta_{j, 35}^{p}$ is the allocation in style $j$ of pension plan $p$ calculated over the 35 -month window and $\beta_{j, 36}^{p}$ is obtained from monthly returns over the next window of 36 -month observations.

\subsection{Shortcomings of the LSV herding measure}

Financial literature has pointed out some shortcomings and limitations to the LSV measure. Oehler (1998) firstly claims that LSV measure is designed to capture buying herding, although potential convergent patterns on the selling side are also relevant. Based on this criticism, our study is focused on both buying and selling herding. 
Secondly, Oehler (1998) indicates that the parameter $p(t)$ calculated according to the LSV metric (see equation 3) does not properly capture the herding level for each asset class. Therefore, instead of using a unique $p(t)$ for all the basic assets as shown in LSV metric, it is relevant to consider the possibility of working out a $p(t)$ value for each style. This author indicates that "the $p(t)$ adjustment leads to a lack of information because averaging procedure (across all stocks) and does not allow to compare stock by stock separately". This drawback might also be affecting our analysis of style allocations and is connected with some additional concerns about the $p(t)$ values pointed out by Wylie (2005). Concretely, Wylie (2005) indicates that the probability of buying or selling a stock in a given period could not be the same, given that managers cannot undertake short sales, and, as a result, only managers having an initial holding are able to sell it. Additionally, the probability of buying a certain stock also seems to be conditioned by the size of the initial holding in the stock.

The above concerns about the values of $p(t)$ calculated according to LSV metric lead us to check the existence of a relationship between the previous exposures and the probability of increasing (decreasing) them in the next period. We find a high statistical significance in this relationship when equity and cash exposures are analyzed (see Appendix A). However, only Figures A.1 and A.2 show a clear and inverse trend between the previous exposure and the probability of increasing the style weight. This finding justifies our calculation of $p(t)$ values that take into account the strategic allocation of the previous period ( $p^{\prime}(t)$ values henceforth) in the analysis of herding in both equity styles (large and small caps).

The calculation of $p^{\prime}(t)$ values can be tackled through both a parametric and a nonparametric regression. However, the use of a non-parametric method is more advisable since parametric regressions could create a generated regressor bias ${ }^{2}$ because the independent variable are the style weights estimated and include estimation errors.

We thus propose the calculation of the $p^{\prime}(t)$ values using a non-parametric kernel method given its utility in the case of unknown forms of the relationship between the two variables (the probability of increasing the exposure to a certain style and the previous exposure). Therefore, the non-parametric method provides us the probability of increasing the exposure for each value of $\beta_{j, 35}^{p}$. These probabilities are calculated from the exposures of each pension plan $p$ in each rolling window and the information about whether each exposure is higher or lower than the allocation in the previous period. This method is described in Appendix B.

Finally, Bikhchandani and Sharma (2000) indicate two limitations of LSV measure. The first limitation is that this measure only uses the number of managers on the two sides of the market without any regard for the amount of stocks they buy or sell to assess the extent of herding. Therefore, this metric disregards the value of manager trades and

\footnotetext{
2 The parametric regression of Appendix A was used to demonstrate that the tendency shown by Figures A.1 and A.2 is statistically significant.
} 
can overlook herding which can in fact be present. ${ }^{3}$ For this reason, some authors like Wermers (1999) and Voronkova and Bohl (2005) advocate the use of a complementary measure that collects information about the amount of stocks bought or sold by each manager. This measure referred to as the dollar ratio and volume herding in financial literature is defined in our study as the amount ratio, as it considers the magnitude or value of the increases or reductions in the strategic allocation of each period. The ratio is expressed as follows:

$$
\text { Amount Ratio }=£ p(j, t)-£ p(t)
$$

where:

$$
\begin{gathered}
£ p(j, t)=\frac{£ B(j, t)}{£ B(j, t)+£ S(j, t)}, \\
£ p(t)=\frac{\sum_{j=1}^{k} £ B(j, t)}{\sum_{j=1}^{k} £ B(j, t)+\sum_{j=1}^{k} £ S(j, t)} .
\end{gathered}
$$

$£ B(j, t)$ and $£(j, t)$ are the magnitude of the increases and decreases in the benchmark $j$ over period $t, £ p(j, t)$ is the percentage of the magnitude of increases in benchmark $j$ in period $t$; and $£ p(t)$ is the expected proportion of the magnitude of the increases in that period relative to the amount traded aggregated across all styles.

With respect to the second limitation, this metric could be used to evaluate the level of herding in a given period from a cross-sectional point of view, but it cannot detect whether certain managers constantly tend to imitate others over time (time-series perspective). As a consequence, Andreu et al. (2009) propose a time-series analysis to test intertemporal herding patterns. These authors compare the variations in the investments of each pension plan to those carried out by the rest of managers. Applying this method to our analysis, we compute time-series regressions for each pension plan $p$ as follows:

$$
\Delta \beta_{p j, t}=h_{p n} \cdot \Delta \beta_{n j, t}+e_{p j, t},
$$

where: $\Delta \beta_{p j, t}=\beta_{j, 36}^{p}-\beta_{j, 35}^{p}$, that is, the monthly variation in the strategic allocation $j$ in period $t$ of pension plan $p ; \Delta \beta_{n j, t}=\beta_{j, 36}^{n}-\beta_{j, 35}^{n}$, that is, the monthly variation in the strategic allocation $j$ in period $t$ of the equally-weighted portfolio $n$ that encompasses every pension plan except $p ; h_{p n}$ is the slope of the regression and $e_{p j, t}$ is the residual term of the regression.

The slope of this regression indicates the convergence in the strategic changes on benchmark $j$ allocated by each pension plan $p$ and by the rest of the pension plans. A positive and statistically significant $h_{p n}$ would provide evidence of intertemporal herding in the allocation analyzed.

\footnotetext{
${ }^{3}$ Think about a situation in which the buyers and sellers are similar in number but the buyers collectively demand a substantial amount of the stock while the sellers only put a relatively small amount into the market. In such a situation, though herding into stocks exists, the LSV measure would not capture it.
} 


\subsection{Robustness analysis}

Some previous studies of herding using portfolio holdings can be biased since we could observe managers with higher dollar value in a stock and however, the proportion of this stock in the portfolio could have been reduced. Grinblatt et al. (1995) point out that the dollar value of a position will increase (decrease) if the stock has a positive (negative) return hence leading to artificial evidence of herding. Similarly, the return of the benchmarks selected could affect the movements in the style exposures thereby, biasing our findings.

For that reason, we carry out a robustness analysis that takes into account "passive style portfolios", that is portfolios that maintain their given investment style along time. Additionally, we compare the results obtained with the abovementioned herding analyses of our sample of UK pension plans with the results obtained by passive style portfolios to isolate potential artificial herding. The robustness analysis is carried out following the next steps:

Step 1: we estimate equation (5) considering all information available for each pension plan $p$ to calculate the long-term beta of each style for each pension plan. Hence, the estimated parameters obtained for each portfolio $\left(\hat{\beta}_{0}^{p}, \hat{\beta}_{1}^{p}, \hat{\beta_{2}^{p}}, \hat{\beta}_{3}^{p}\right.$ and $\left.\hat{\beta}_{4}^{p}\right)$ are used as style weights of the passive portfolios.

Step 2: we calculate the expected return of each "passive style portfolio" in each month $t$ :

$$
\begin{aligned}
& E\left(R_{t}^{p}\right)=\hat{\beta_{0}^{p}}+\hat{\beta_{1}^{p}} R_{M S C I \text { Worldl } \arg e+\text { mid }, t}+\hat{\beta_{2}^{p}} R_{\text {MSCIWorldSmall }, t}+ \\
& \hat{\beta_{3}^{p}} R_{10 y \text { PublicBonds }, t}+\hat{\beta_{4}^{p}} R_{\text {Repos }, t} \text {. }
\end{aligned}
$$

Step 3: to apply the rolling window approach, for each pension plan $p$ and for each 35-month rolling window composed of 35 observed monthly returns, we add a new observation, the monthly expected return $E\left(R_{t}^{p}\right)$ calculated as in Step 2. Then, we estimate the style exposures of this 36 -month rolling window $\left(\beta_{j, 36}^{*}\right)$.

Step 4: we compare $\beta_{j, 35}^{p}$ (see expression 6) with the 36-month rolling window betas estimated in Step $3\left(\beta_{j, 36}^{*}\right)$ to determine if each pension plan is a buying or selling portfolio in the style $j$ and to determine the herding levels of passive style portfolios.

Step 5: we calculate the difference between the herding levels shown by our sample of UK pension plans and the herding levels shown by the passive style portfolios to provide measures that reflect the herding produced by managers' decisions. Hence, the key point of the new herding levels (reported in Panel B of Tables 4 to 7) is to isolate artificial herding that cannot be attributable to managers decisions (e.g. style variations due to the long-term investment style or the benchmark revalorization).

Finally, trading decisions are also influenced by net fund flows (Wylie 2005). However, the allocation of new money does not necessarily imply variations on the current strategic style allocations. Therefore, fund inflows do not have an impact on our style allocation analysis as opposed to the analyses of herding in portfolio holdings. 


\section{Empirical results}

\subsection{Style analysis results}

Table 3 reports summary statistics of the style allocations followed by UK pension plans. The table shows that the model fits well, as indicated by the high average $R^{2}$ coefficient $(82.55 \%)$. Hence, the model has strong explanatory power. Second, as stressed by Comer (2006), the results emphasize the importance of modelling the bond and cash portions of balanced portfolios. Concretely, the mean exposures in the fixed-income and cash index represent a total of $33.38 \%$ of the portfolios. Nevertheless, the most important weight is shown by the equity allocations $(66.62 \%)$.

Table 3. Summary statistics of the style analysis

\begin{tabular}{lcccc}
\hline & Mean & Median & 25th percentile & 75th percentile \\
\hline$\beta_{0}$ & 0.0001 & 0.0000 & -0.0008 & 0.0008 \\
\hline$\beta_{1}$ (Equity Large + Mid caps) & 0.4710 & 0.4832 & 0.3531 & 0.6012 \\
\hline$\beta_{2}$ (Equity Small caps) & 0.1952 & 0.1789 & 0.0671 & 0.2872 \\
\hline$\beta_{3}$ (Fixed-income) & 0.1261 & 0.0000 & 0.0000 & 0.3132 \\
\hline$\beta_{4}$ (Cash) & 0.2077 & 0.2819 & 0.0000 & 0.3539 \\
\hline $\mathrm{R}^{2}$ & 0.8255 & 0.8480 & 0.7870 & 0.8760 \\
\hline
\end{tabular}

Notes: The table shows cross-sectional statistics of the estimated results from Sharpe's style analysis for our sample of UK pension plans from June 2000 to December 2007.

\subsection{Herding results applying the traditional LSV measure}

Table 4 shows the herding results using the traditional LSV measure. It is divided into two panels. Panel A shows the herding level of our sample of UK pension plans while Panel B shows the herding level once we control for artificial herding (see Section 2.5 for the procedure of the robustness analysis).

Panel A highlights an average herding level of $12.57 \%$, a figure higher than those previously reported in the US and in the UK market when examining portfolio holdings (see, e.g. the level of $2.7 \%$ revealed by Lakonishok et al. 1992). This finding could be attributed to the analysis of herding in style allocations instead of in particular stocks (Ferruz et al. 2008 find an overall herding level of 13.26\% when examining style herding for the Spanish market). Furthermore, our results indicate a similar herding level to that reported using portfolio holdings in other less mature markets (see, e.g., the level of $22.6 \%$ shown in Voronkova, Bohl 2005 for the Polish market). However, the herding level declines to an average of $6.36 \%$ when artificial herding is removed (Panel B of Table 4).

Additionally, we observe a higher herding behavior in the equity style allocations $\left(\beta_{1}\right.$ and $\beta_{2}$ ), the most relevant assets in the funds. Note that this higher level of herding corresponds to a higher number of months in which this phenomenon is detected. 
Table 4. Herding results based on the LSV measure

\begin{tabular}{|c|c|c|c|c|c|c|}
\hline \multicolumn{7}{|c|}{ Panel A: Herding results based on the LSV measure } \\
\hline$\beta_{1}$ (Equities) & $2003 *$ & 2004 & 2005 & 2006 & 2007 & 2003-2007 \\
\hline \multirow[t]{2}{*}{$\mathrm{BH}$} & $25.06 \%(4)$ & $24.38 \%(8)$ & $14.94 \%(4)$ & $14.39 \%(6)$ & $9.48 \%(7)$ & $18.34 \%(29)$ \\
\hline & 0.00 & 0.00 & 0.00 & 0.00 & 0.00 & 0.00 \\
\hline \multirow[t]{2}{*}{$\mathrm{SH}$} & $10.12 \%(3)$ & $8.61 \%(4)$ & $16.24 \%(8)$ & $17.18 \%(6)$ & $17.28 \%(5)$ & $14.78 \%(26)$ \\
\hline & 0.00 & 0.00 & 0.00 & 0.00 & 0.00 & 0.00 \\
\hline \multirow[t]{2}{*}{ Average } & $17.59 \%$ & $16.49 \%$ & $15.59 \%$ & $15.79 \%$ & $13.38 \%$ & $16.56 \%$ \\
\hline & 0.00 & 0.00 & 0.00 & 0.00 & 0.00 & 0.00 \\
\hline \multicolumn{7}{|c|}{$\beta_{2}$ (Small caps) } \\
\hline \multirow[t]{2}{*}{$\mathrm{BH}$} & $0.98 \%(1)$ & $15.28 \%(4)$ & $18.80 \%(6)$ & $14.06 \%(6)$ & $13.40 \%(6)$ & $13.60 \%(23)$ \\
\hline & 0.84 & 0.00 & 0.00 & 0.00 & 0.00 & 0.00 \\
\hline \multirow[t]{2}{*}{$\mathrm{SH}$} & $33.68 \%(6)$ & $26.92 \%(8)$ & $13.79 \%(6)$ & $12.97 \%(6)$ & $9.75 \%(5)$ & $19.96 \%(31)$ \\
\hline & 0.00 & 0.00 & 0.00 & 0.00 & 0.00 & 0.00 \\
\hline \multirow[t]{2}{*}{ Average } & $17.33 \%$ & $21.10 \%$ & $16.29 \%$ & $13.51 \%$ & $11.58 \%$ & $16.78 \%$ \\
\hline & 0.00 & 0.00 & 0.00 & 0.00 & 0.00 & 0.00 \\
\hline \multicolumn{7}{|c|}{$\beta_{3}$ (Fixed-income) } \\
\hline \multirow[t]{2}{*}{$\mathrm{BH}$} & $13.24 \%(4)$ & $5.15 \%(4)$ & $7.10 \%(4)$ & $3.57 \%(5)$ & $9.21 \%(5)$ & $7.87 \%(22)$ \\
\hline & 0.00 & 0.05 & 0.14 & 0.42 & 0.00 & 0.00 \\
\hline \multirow[t]{2}{*}{$\mathrm{SH}$} & $6.10 \%(3)$ & $13.60 \%(6)$ & $9.75 \%(6)$ & $4.06 \%(3)$ & $5.22 \%(3)$ & $8.23 \%(21)$ \\
\hline & 0.02 & 0.00 & 0.01 & 0.34 & 0.05 & 0.00 \\
\hline \multirow[t]{2}{*}{ Average } & $9.67 \%$ & $9.37 \%$ & $8.43 \%$ & $3.82 \%$ & $7.22 \%$ & $8.05 \%$ \\
\hline & 0.00 & 0.00 & 0.00 & 0.22 & 0.00 & 0.00 \\
\hline \multicolumn{7}{|c|}{$\beta_{4}$ (Cash) } \\
\hline \multirow[t]{2}{*}{$\mathrm{BH}$} & $13.78 \%(4)$ & $5.01 \%(4)$ & $10.02 \%(4)$ & $10.84 \%(5)$ & $8.61 \%(5)$ & $10.03 \%(22)$ \\
\hline & 0.00 & 0.04 & 0.00 & 0.00 & 0.00 & 0.00 \\
\hline \multirow[t]{2}{*}{$\mathrm{SH}$} & $1.01 \%(1)$ & $3.14 \%(4)$ & $14.44 \%(7)$ & $8.59 \%(7)$ & $8.31 \%(4)$ & $7.71 \%(23)$ \\
\hline & 0.93 & 0.23 & 0.00 & 0.00 & 0.00 & 0.00 \\
\hline \multirow[t]{2}{*}{ Average } & $7.40 \%$ & $4.08 \%$ & $12.23 \%$ & $9.72 \%$ & $8.46 \%$ & $8.87 \%$ \\
\hline & 0.04 & 0.03 & 0.00 & 0.00 & 0.00 & 0.00 \\
\hline Aggregate & $13.00 \%$ & $12.76 \%$ & $13.14 \%$ & $10.71 \%$ & $10.16 \%$ & $12.57 \%$ \\
\hline
\end{tabular}

Notes: Panel A shows the herding level of UK pension plans based on LSV measure while Panel B shows these herding levels once we control for artificial herding. Each panel shows the results for the four style allocations considered for both buying $(\mathrm{BH})$ and selling $(\mathrm{SH})$ managers as well as the average. The annual herding level is calculated considering the sum of the herding levels in the months where this phenomenon is detected divided by the number of months analyzed each year. The herding level is expressed in percentage terms along with the number of months in which this behavior is observed in parenthesis. Additionally, the table also reports the results for the whole time period 
End of Table 4

\begin{tabular}{|c|c|c|c|c|c|c|}
\hline \multicolumn{7}{|c|}{ Panel B: Robustness analysis } \\
\hline$\beta_{1}$ (Equities) & $2003 *$ & 2004 & 2005 & 2006 & 2007 & $2003-2007$ \\
\hline \multirow[t]{2}{*}{$\mathrm{BH}$} & $4.16 \%(2)$ & $5.09 \%(5)$ & $14.49 \%(4)$ & $11.65 \%(5)$ & $5.15 \%(4)$ & $8.24 \%(20)$ \\
\hline & 0.18 & 0.01 & 0.00 & 0.00 & 0.00 & 0.00 \\
\hline \multirow[t]{2}{*}{$\mathrm{SH}$} & $3.21 \%(1)$ & $4.88 \%(4)$ & $11.13 \%(5)$ & $9.10 \%(4)$ & $11.24 \%(5)$ & $8.07 \%(19)$ \\
\hline & 0.18 & 0.01 & 0.00 & 0.00 & 0.00 & 0.00 \\
\hline \multirow[t]{2}{*}{ Average } & $3.68 \%$ & $4.98 \%$ & $12.81 \%$ & $10.38 \%$ & $8.20 \%$ & $8.16 \%$ \\
\hline & 0.16 & 0.00 & 0.00 & 0.00 & 0.00 & 0.00 \\
\hline \multicolumn{7}{|c|}{$\beta_{2}$ (Small caps) } \\
\hline \multirow[t]{2}{*}{$\mathrm{BH}$} & - & $5.25 \%(3)$ & $5.24 \%(2)$ & $6.53 \%(3)$ & $9.43 \%(5)$ & $5.47 \%(13)$ \\
\hline & - & 0.03 & 0.08 & 0.01 & 0.00 & 0.00 \\
\hline \multirow[t]{2}{*}{$\mathrm{SH}$} & $14.62 \%(4)$ & $11.88 \%(5)$ & $12.70 \%(6)$ & $12.97 \%(6)$ & $4.24 \%(3)$ & $11.17 \%(24)$ \\
\hline & 0.00 & 0.00 & 0.00 & 0.00 & 0.05 & 0.00 \\
\hline \multirow[t]{2}{*}{ Average } & $7.31 \%$ & $8.56 \%$ & $8.97 \%$ & $9.75 \%$ & $6.84 \%$ & $8.32 \%$ \\
\hline & 0.03 & 0.00 & 0.00 & 0.00 & 0.00 & 0.00 \\
\hline \multicolumn{7}{|c|}{$\beta_{3}$ (Fixed-income) } \\
\hline \multirow[t]{2}{*}{$\mathrm{BH}$} & $4.60 \%(4)$ & $4.89 \%(4)$ & $4.50 \%(3)$ & $1.40 \%(2)$ & $4.04 \%$ (3) & $3.86 \%(16)$ \\
\hline & 0.07 & 0.06 & 0.39 & 0.91 & 0.16 & 0.01 \\
\hline \multirow[t]{2}{*}{ SH } & $0.24 \%(1)$ & $2.84 \%(4)$ & $8.18 \%(5)$ & $3.15 \%(3)$ & $3.96 \%(2)$ & $3.79 \%(15)$ \\
\hline & 0.95 & 0.26 & 0.03 & 0.46 & 0.28 & 0.02 \\
\hline \multirow[t]{2}{*}{ Average } & $2.42 \%$ & $3.87 \%$ & $6.34 \%$ & $2.28 \%$ & $4.00 \%$ & $3.83 \%$ \\
\hline & 0.28 & 0.04 & 0.04 & 0.57 & 0.08 & 0.00 \\
\hline \multicolumn{7}{|c|}{$\beta_{4}(\mathrm{Cash})$} \\
\hline \multirow[t]{2}{*}{$\mathrm{BH}$} & $5.82 \%(3)$ & $3.01 \%(4)$ & $9.97 \%(4)$ & $8.04 \%$ (4) & $6.20 \%$ & $6.64 \%(18)$ \\
\hline & 0.21 & 0.22 & 0.00 & 0.00 & 0.03 & 0.00 \\
\hline \multirow[t]{2}{*}{ SH } & - & $1.01 \%(3)$ & $6.16 \%(5)$ & $4.26 \%(7)$ & $6.14 \%(4)$ & $3.64 \%(19)$ \\
\hline & - & 0.77 & 0.00 & 0.01 & 0.01 & 0.00 \\
\hline \multirow[t]{2}{*}{ Average } & $2.91 \%$ & $2.01 \%$ & $8.06 \%$ & $6.15 \%$ & $6.17 \%$ & $5.14 \%$ \\
\hline & 0.53 & 0.33 & 0.00 & 0.00 & 0.00 & 0.00 \\
\hline Aggregate & $4.08 \%$ & $4.85 \%$ & $9.05 \%$ & $7.14 \%$ & $6.30 \%$ & $6.36 \%$ \\
\hline
\end{tabular}

analyzed (June 2003 - December 2007). The p-values associated to each herding level appear below the metric and have been calculated according to a normal distribution since if $n$ is large enough the binomial distribution converges asymptotically to this distribution.

*Although the return-based style analysis of Sharpe (1992) is carried out from June 2000 to December 2007, the use of 36-month rolling windows leads us to examine herding behavior from June 2003 to December 2007. Therefore, in 2003 we can only consider seven months. 


\subsection{Herding results applying alternative methods}

\subsubsection{Herding results with accurate values of $p(t)$}

Table 5 shows the herding level when using the values of the probability of increasing the equity exposures obtained from the non-parametric kernel method (see Section 2.4 and Appendix B). This analysis has only been applied to equity exposures since Figures A.1 and A.2 depict that only in equities there is a significant relationship between the probability of increasing the exposure and the previous style weight.

Table 5 shows that the average herding level in $\beta_{1}$ is reduced from $8.16 \%$ when using LSV measure to $7.63 \%$ when using $p^{\prime}(t)$ values and the herding level in $\beta_{2}$ is also reduced from $8.32 \%$ to $7.99 \%$.

\subsubsection{Herding results from a quantitative perspective}

Table 6 gathers the results obtained through the use of the amount ratio (Equation 7). The structure of this table is similar to Tables 4 and 5. As we could expect, this table provides evidence of herding behavior from a quantitative perspective, being this level slightly higher than the herding level reported through the LSV measure $(7.93 \%$ versus $6.36 \%)$.

Table 5. Herding results based on $p^{\prime}(t)$

\begin{tabular}{ccccccc}
\hline \multicolumn{7}{c}{ Panel A: Herding results based on p'(t) } \\
\hline$\beta_{1}$ (Equities) & $2003 *$ & 2004 & 2005 & 2006 & 2007 & $2003-2007$ \\
\hline BH & $17.89 \%(4)$ & $20.89 \%(8)$ & $11.93 \%(4)$ & $14.97 \%(6)$ & $8.41 \%(5)$ & $15.51 \%(27)$ \\
& 0.00 & 0.00 & 0.00 & 0.00 & 0.00 & 0.00 \\
SH & $15.75 \%(3)$ & $12.23 \%(4)$ & $15.39 \%(8)$ & $12.09 \%(5)$ & $15.41 \%(5)$ & $14.89 \%(25)$ \\
& 0.00 & 0.00 & 0.00 & 0.00 & 0.00 & 0.00 \\
Average & $16.82 \%$ & $16.56 \%$ & $13.66 \%$ & $13.53 \%$ & $11.91 \%$ & $15.20 \%$ \\
& 0.00 & 0.00 & 0.00 & 0.00 & 0.00 & 0.00 \\
\hline BH & $2.55 \%(1)$ & $13.91 \%(4)$ & $18.61 \%(6)$ & $19.38 \%(6)$ & $18.32 \%(6)$ & $15.78 \%(23)$ \\
& 0.01 & 0.00 & 0.00 & 0.00 & 0.00 & 0.00 \\
SH & $21.54 \%(6)$ & $17.84 \%(8)$ & $15.33 \%(6)$ & $15.4 \%(6)$ & $8.12 \%(6)$ & $16.29 \%(32)$ \\
& 0.00 & 0.00 & 0.00 & 0.00 & 0.00 & 0.00 \\
Average & $12.04 \%$ & $15.88 \%$ & $16.97 \%$ & $17.39 \%$ & $13.22 \%$ & $16.03 \%$ \\
& 0.00 & 0.00 & 0.00 & 0.00 & 0.00 & 0.00 \\
\hline
\end{tabular}


End of Table 5

\begin{tabular}{ccccccc}
\hline \multicolumn{7}{c}{ Panel B: Robustness analysis } \\
\hline$\beta_{1}$ (Equities) & $2003 *$ & 2004 & 2005 & 2006 & 2007 & $2003-2007$ \\
\hline BH & $5.66 \%(2)$ & $6.99 \%(5)$ & $11.20 \%(4)$ & $10.98 \%(6)$ & $4.17 \%(3)$ & $7.87 \%(20)$ \\
& 0.08 & 0.00 & 0.00 & 0.00 & 0.05 & 0.00 \\
SH & $4.39 \%(2)$ & $5.37 \%(3)$ & $8.90 \%(6)$ & $7.62 \%(4)$ & $10.19 \%(5)$ & $7.39 \%(20)$ \\
& 0.01 & 0.02 & 0.00 & 0.00 & 0.00 & 0.00 \\
Average & $5.02 \%$ & $6.18 \%$ & $10.05 \%$ & $9.30 \%$ & $7.18 \%$ & $7.63 \%$ \\
& 0.00 & 0.00 & 0.00 & 0.00 & 0.00 & 0.00 \\
\hline \multirow{2}{*}{ BH } & - & $6.09 \%(3)$ & $6.83 \%(4)$ & $8.02 \%(4)$ & $11.41 \%(5)$ & $6.69 \%(16)$ \\
& - & 0.01 & 0.00 & 0.00 & 0.00 & 0.00 \\
SH & $6.60 \%(4)$ & $6.19 \%(5)$ & $14.80 \%(6)$ & $15.40 \%(6)$ & $2.97 \%(4)$ & $9.28 \%(25)$ \\
& 0.00 & 0.00 & 0.00 & 0.00 & 0.11 & 0.00 \\
Average & $3.30 \%$ & $6.14 \%$ & $10.82 \%$ & $11.71 \%$ & $7.19 \%$ & $7.99 \%$ \\
& 0.02 & 0.00 & 0.00 & 0.00 & 0.00 & 0.00 \\
\hline
\end{tabular}

Notes: Panel A shows the herding level of UK pension plans based on $p^{\prime}(t)$ while Panel B shows these herding levels once we control for artificial herding. Each panel shows the results for the Large $+\mathrm{Mid}$ cap equity and Small cap equity style allocations for both buying (BH) and selling (SH) managers as well as the average.

\subsubsection{Herding results from a time-series perspective}

The results of intertemporal herding are shown in Table 7. Panel A shows a high number of pension managers (more than 65\%) with herding behavior over time in relation to the rest of the portfolios analyzed. We also highlight that this value reaches more than $95 \%$ when the equity allocation in large and medium caps is studied. These results provide evidence for a global trend towards herding over time among UK pension plans.

As in previous sections, we perform the robustness analysis and show the results in Panel B of Table 7. These results confirm the existence of significant intertemporal herding in a high number of portfolios when studying the variation in the equity exposures $\left(\beta_{1}\right.$ and $\left.\beta_{2}\right)$. However, the number of portfolios with significant intertemporal herding is reduced in the fixed-income and cash allocations. This finding is consistent with the relevance of equity exposures in the investment vocation of the portfolios analyzed. 
Table 6. Herding results based on the amount ratio

\begin{tabular}{|c|c|c|c|c|c|c|}
\hline \multicolumn{7}{|c|}{ Panel A: Herding results based on the amount ratio } \\
\hline$\beta_{1}$ (Equities) & 2003* & 2004 & 2005 & 2006 & 2007 & 2003-2007 \\
\hline \multirow[t]{2}{*}{$\mathrm{BH}$} & $29.05 \%$ & $28.89 \%(8)$ & $13.06 \%(4)$ & $17.49 \%(6)$ & $15.63 \%(7)$ & $21.66 \%(29)$ \\
\hline & 0.00 & 0.00 & 0.00 & 0.00 & 0.00 & 0.00 \\
\hline \multirow[t]{2}{*}{$\mathrm{SH}$} & $8.96 \%(3)$ & $13.33 \%(4)$ & $22.20 \%(8)$ & $17.93 \%(6)$ & $19.56 \%(5)$ & $17.56 \%(26)$ \\
\hline & 0.00 & 0.00 & 0.00 & 0.00 & 0.00 & 0.00 \\
\hline \multirow[t]{2}{*}{ Average } & $19.01 \%$ & $21.11 \%$ & $17.63 \%$ & $17.71 \%$ & $17.60 \%$ & $19.61 \%$ \\
\hline & 0.00 & 0.00 & 0.00 & 0.00 & 0.00 & 0.00 \\
\hline \multicolumn{7}{|c|}{$\beta_{2}$ (Small caps) } \\
\hline \multirow[t]{2}{*}{$\mathrm{BH}$} & $2.29 \%(1)$ & $16.29 \%(4)$ & $19.24 \%(6)$ & $18.38 \%(6)$ & $18.53 \%(6)$ & $16.22 \%(23)$ \\
\hline & 0.02 & 0.00 & 0.00 & 0.00 & 0.00 & 0.00 \\
\hline \multirow[t]{2}{*}{$\mathrm{SH}$} & $32.24 \%(6)$ & $30.93 \%(8)$ & $16.64 \%(6)$ & $14.52 \%(6)$ & $15.11 \%(6)$ & $22.70 \%(32)$ \\
\hline & 0.00 & 0.00 & 0.00 & 0.00 & 0.00 & 0.00 \\
\hline \multirow[t]{2}{*}{ Average } & $17.26 \%$ & $23.61 \%$ & $17.94 \%$ & $16.45 \%$ & $16.82 \%$ & $19.46 \%$ \\
\hline & 0.00 & 0.00 & 0.00 & 0.00 & 0.00 & 0.00 \\
\hline \multicolumn{7}{|c|}{$\beta_{3}$ (Fixed-income) } \\
\hline \multirow[t]{2}{*}{$\mathrm{BH}$} & $16.22 \%(2)$ & $11.86 \%(5)$ & $20.85 \%(6)$ & $11.04 \%(4)$ & $22.60 \%(7)$ & $17.43 \%(24)$ \\
\hline & 0.00 & 0.00 & 0.00 & 0.01 & 0.00 & 0.00 \\
\hline \multirow[t]{2}{*}{ SH } & $15.38 \%(5)$ & $22.06 \%(7)$ & $22.47 \%(6)$ & $23.02 \%(8)$ & $13.04 \%(5)$ & $20.38 \%(31)$ \\
\hline & 0.00 & 0.00 & 0.00 & 0.00 & 0.00 & 0.00 \\
\hline \multirow[t]{2}{*}{ Average } & $15.80 \%$ & $16.96 \%$ & $21.66 \%$ & $17.03 \%$ & $17.82 \%$ & $18.90 \%$ \\
\hline & 0.00 & 0.00 & 0.00 & 0.00 & 0.00 & 0.00 \\
\hline \multicolumn{7}{|c|}{$\beta_{4}($ Cash $)$} \\
\hline \multirow[t]{2}{*}{$\mathrm{BH}$} & $22.47 \%(4)$ & $22.64 \%(7)$ & $21.96 \%(7)$ & $22.40 \%(8)$ & $12.04 \%(4)$ & $21.33 \%(30)$ \\
\hline & 0.00 & 0.00 & 0.00 & 0.00 & 0.00 & 0.00 \\
\hline \multirow[t]{2}{*}{ SH } & $13.44 \%(3)$ & $13.37 \%(5)$ & $13.79 \%(5)$ & $13.83 \%(4)$ & $21.09 \%(8)$ & $15.99 \%(25)$ \\
\hline & 0.00 & 0.00 & 0.00 & 0.00 & 0.00 & 0.00 \\
\hline \multirow[t]{2}{*}{ Average } & $17.96 \%$ & $18.01 \%$ & $17.87 \%$ & $18.11 \%$ & $16.57 \%$ & $18.66 \%$ \\
\hline & 0.00 & 0.00 & 0.00 & 0.00 & 0.00 & 0.00 \\
\hline Aggregate & $17.51 \%$ & $19.92 \%$ & $18.78 \%$ & $17.33 \%$ & $17.20 \%$ & $19.16 \%$ \\
\hline
\end{tabular}


End of Table 6

\begin{tabular}{|c|c|c|c|c|c|c|}
\hline \multirow[b]{2}{*}{$\beta_{1}$ (Equities) } & \multicolumn{6}{|c|}{ Panel B: Robustness analysis } \\
\hline & $2003 *$ & 2004 & 2005 & 2006 & 2007 & 2003-2007 \\
\hline \multirow[t]{2}{*}{$\mathrm{BH}$} & $6.42 \%(3)$ & $6.84 \%(5)$ & $10.92 \%(4)$ & $14.91 \%(5)$ & $7.04 \%(4)$ & $9.32 \%(21)$ \\
\hline & 0.02 & 0.00 & 0.00 & 0.00 & 0.00 & 0.00 \\
\hline \multirow[t]{2}{*}{ SH } & $2.42 \%(1)$ & $5.49 \%(4)$ & $10.96 \%(5)$ & $8.97 \%(4)$ & $9.00 \%(5)$ & $7.54 \%(19)$ \\
\hline & 0.57 & 0.01 & 0.00 & 0.00 & 0.00 & 0.00 \\
\hline \multirow[t]{2}{*}{ Average } & $4.42 \%$ & $6.16 \%$ & $10.94 \%$ & $11.94 \%$ & $8.02 \%$ & $8.43 \%$ \\
\hline & 0.05 & 0.00 & 0.00 & 0.00 & 0.00 & 0.00 \\
\hline \multicolumn{7}{|c|}{$\beta_{2}$ (Small caps) } \\
\hline \multirow[t]{2}{*}{$\mathrm{BH}$} & - & $8.32 \%(4)$ & $4.36 \%(3)$ & $7.68 \%(3)$ & $9.84 \%(5)$ & $6.25 \%(15)$ \\
\hline & - & 0.00 & 0.08 & 0.00 & 0.00 & 0.00 \\
\hline \multirow[t]{2}{*}{$\mathrm{SH}$} & $9.92 \%(4)$ & $9.70 \%(6)$ & $14.02 \%(6)$ & $14.52 \%(6)$ & $6.98 \%(4)$ & $11.07 \%(26)$ \\
\hline & 0.00 & 0.00 & 0.00 & 0.00 & 0.00 & 0.00 \\
\hline \multirow[t]{2}{*}{ Average } & $4.96 \%$ & $9.01 \%$ & $9.19 \%$ & $11.10 \%$ & $8.41 \%$ & $8.66 \%$ \\
\hline & 0.03 & 0.00 & 0.00 & 0.00 & 0.00 & 0.00 \\
\hline \multicolumn{7}{|c|}{$\beta_{3}$ (Fixed-income) } \\
\hline \multirow[t]{2}{*}{$\mathrm{BH}$} & $0.11 \%(1)$ & $6.94 \%(4)$ & $10.28 \%(3)$ & $3.59 \%$ & $4.93 \%(3)$ & $5.35 \%(14)$ \\
\hline & 0.98 & 0.01 & 0.22 & 0.47 & 0.06 & 0.00 \\
\hline \multirow[t]{2}{*}{ SH } & $6.88 \%(4)$ & $2.26 \%(4)$ & $10.77 \%(5)$ & $18.26 \%(7)$ & $10.53 \%(4)$ & $9.84 \%(24)$ \\
\hline & 0.01 & 0.34 & 0.00 & 0.00 & 0.00 & 0.00 \\
\hline \multirow[t]{2}{*}{ Average } & $3.50 \%$ & $4.60 \%$ & $10.53 \%$ & $10.92 \%$ & $7.73 \%$ & $7.59 \%$ \\
\hline & 0.13 & 0.01 & 0.00 & 0.00 & 0.00 & 0.00 \\
\hline \multicolumn{7}{|c|}{$\beta_{4}(\mathrm{Cash})$} \\
\hline \multirow[t]{2}{*}{$\mathrm{BH}$} & $12.05 \%(4)$ & $1.08 \%(3)$ & $11.31 \%(6)$ & $18.71 \%(7)$ & $9.60 \%(3)$ & $10.50 \%(23)$ \\
\hline & 0.00 & 0.78 & 0.00 & 0.00 & 0.00 & 0.00 \\
\hline \multirow[t]{2}{*}{$\mathrm{SH}$} & - & $5.57 \%(3)$ & $3.24 \%(2)$ & $2.78 \%(2)$ & $5.68 \%(4)$ & $3.57 \%(11)$ \\
\hline & - & 0.07 & 0.25 & 0.29 & 0.02 & 0.01 \\
\hline \multirow[t]{2}{*}{ Average } & $6.03 \%$ & $3.32 \%$ & $7.27 \%$ & $10.74 \%$ & $7.64 \%$ & $7.03 \%$ \\
\hline & 0.12 & 0.16 & 0.00 & 0.00 & 0.00 & 0.00 \\
\hline Aggregate & $4.73 \%$ & $5.77 \%$ & $9.48 \%$ & $11.18 \%$ & $7.95 \%$ & $7.93 \%$ \\
\hline
\end{tabular}

Notes: Panel A shows the herding level of UK pension plans based on the amount ratio while Panel $\mathrm{B}$ shows these herding levels once we control for artificial herding. Each panel shows the results for the four style allocations considered for both buying $(\mathrm{BH})$ and selling $(\mathrm{SH})$ managers as well as the average. 
Table 7. Intertemporal herding results

\begin{tabular}{|c|c|c|c|c|c|c|c|c|}
\hline \multicolumn{5}{|c|}{ Panel A: Intertemporal herding results } & \multicolumn{4}{|c|}{ Panel B: Robustness analysis } \\
\hline & $h_{p n}>0$ & Average & $h_{p n}<0$ & Average & $h_{p n}>0$ & Average & $h_{p n}<0$ & Average \\
\hline $\begin{array}{l}\text { Significant } \beta_{1} \\
\text { (Equities) }\end{array}$ & $\begin{array}{c}164 \\
(96.47 \%)\end{array}$ & 0.0010 & - & - & $\begin{array}{c}159 \\
(93.53 \%)\end{array}$ & 0.0011 & - & - \\
\hline $\begin{array}{l}\text { Not Significant } \beta_{1} \\
\text { (Equities) }\end{array}$ & $\begin{array}{c}5 \\
(2.94 \%)\end{array}$ & 0.3038 & $\begin{array}{c}1 \\
(0.59 \%)\end{array}$ & 0.2031 & - & - & - & - \\
\hline $\begin{array}{l}\text { Significant } \beta_{2} \\
\text { (Small caps) }\end{array}$ & $\begin{array}{c}167 \\
(98.24 \%)\end{array}$ & 0.0007 & - & - & $\begin{array}{c}159 \\
(93.53 \%)\end{array}$ & 0.0005 & - & - \\
\hline $\begin{array}{l}\text { Not Significant } \beta_{2} \\
\text { (Small caps) }\end{array}$ & $\begin{array}{c}2 \\
(1.18 \%)\end{array}$ & 0.3309 & $\begin{array}{c}1 \\
(0.59 \%)\end{array}$ & 0.1614 & - & - & - & - \\
\hline $\begin{array}{l}\text { Significant } \beta_{3} \\
\text { (Fixed-income) }\end{array}$ & $\begin{array}{c}112 \\
(65.88 \%)\end{array}$ & 0.0065 & - & - & $\begin{array}{c}40 \\
(23.53 \%)\end{array}$ & 0.0020 & - & - \\
\hline $\begin{array}{l}\text { Not Significant } \beta_{3} \\
\text { (Fixed-income) }\end{array}$ & $\begin{array}{c}52 \\
(30.59 \%)\end{array}$ & 0.2473 & $\begin{array}{c}6 \\
(3.53 \%)\end{array}$ & 0.6529 & - & - & - & - \\
\hline $\begin{array}{l}\text { Significant } \beta_{4} \\
(\text { Cash })\end{array}$ & $\begin{array}{c}116 \\
(68.24 \%)\end{array}$ & 0.0068 & - & - & $\begin{array}{c}43 \\
(25.29 \%)\end{array}$ & 0.0022 & - & - \\
\hline $\begin{array}{l}\text { Not Significant } \beta_{4} \\
\text { (Cash) }\end{array}$ & $\begin{array}{c}51 \\
(30.00 \%)\end{array}$ & 0.2911 & $\begin{array}{c}3 \\
(1.76 \%)\end{array}$ & 0.5488 & - & - & - & - \\
\hline
\end{tabular}

Notes: Panel A shows the intertemporal herding results of UK pension plans while Panel B shows these herding results once we control for artificial herding. Each panel shows the number of pension managers engaging in intertemporal herding behavior for the four style allocations considered as well as the percentage of the sample that they represent in brackets. The average level of significance is calculated for every $h_{p n}$ that presents a given sign. Only those pension plans with at least 24 monthly variations are considered to obtain robust parameters. Specifically, we examine 170 balanced pension plans.

\section{Conclusions}

This paper focuses on the herding behavior of UK pension managers, an interesting field of research taking into account the influence of institutional managers on stock markets. Specifically, we provide new insights into herding phenomenon by examining managers' decisions with regard to the evolution of their strategic style allocations through the consideration of different methods.

We firstly use the well-known herding measure developed by Lakonishok et al. (1992), finding empirical evidence of herding behavior among UK managers during the entire period. Secondly, we contribute to the literature by studying herding phenomenon through different and complementary analyses. We propose an alternative approach that captures the herding level by using a probability of buying and selling that takes into account the previous exposures of managers to a certain style. That way, we overcome the criticisms received by the traditional measure due to its lack of attention to the fact that the probability of buying and selling cannot be the same since managers cannot undertake short sales and to the fact that this probability is also conditioned by the initial holding or exposure. The results obtained are robust to those previously reported by the traditional metric, although a reduction in the herding level must be highlighted. 
We also evaluate the herding phenomenon from two additional perspectives: a quantitative perspective analyzing the magnitude of the increases and decreases in the strategic allocations instead of the number of managers and a time-series perspective to test the existence of intertemporal herding patterns. The aim of these two analyses is to overcome the limitations of the traditional metric and to show a complete view of the herding phenomenon. We find a herding level similar to that reported by the traditional measure and we demonstrate that this behavior persists over time.

Finally, we carry out a robustness analysis that removes the artificial herding that is not directly attributable to manager decisions in all the approaches considered to determine the existence of true herding behavior in the variations of style exposures. This analysis contributes to the literature about intentional versus artificial herding and represents an avenue for future research. One limitation of the study refers to the time period analyzed because it does not include the years of the global financial crisis. A deeper analysis about how market status affects to both intentional and artificial time is also a line for future research.

\section{Acknowledgements}

The authors would like to acknowledge the financial support provided by the research project ECO2009-12819-C03-02 of Spanish Department of Science. The authors are also grateful to participants of 2010 EFMA Annual Conference held at Aarhus School of Business (Denmark) as well as to participants of $17^{\text {th }}$ Annual Conference Multinational Finance Society held in Barcelona (Spain). Any possible errors contained in this paper are the exclusive responsibility of the authors.

\section{References}

Andreu, L.; Ortiz, C.; Sarto, J. L. 2009. Herding behaviour in strategic asset allocations: new approaches on quantitative and intertemporal imitation, Applied Financial Economics 19: 16491659. http://dx.doi.org/10.1080/09603100903018786

Banerjee, A. 1992. A simple model of herd behaviour, Quarterly Journal of Economics 107: 797-817. http://dx.doi.org/10.2307/2118364

Barberis, N.; Shleifer. A. 2003. Style investing, Journal of Financial Economics 68: 161-199. http://dx.doi.org/10.1016/S0304-405X(03)00064-3

Barberis, N.; Shleifer, A.; Wurgler, J. 2005. Comovement, Journal of Financial Economics 75: 238-317. http://dx.doi.org/10.1016/j.jfineco.2004.04.003

Bikhchandani, S.; Hirshleifer, D.; Welch, I. 1992. A theory of fads, fashion, custom, and cultural change as informational cascades, Journal of Political Economy 100: 992-1026.

http://dx.doi.org/10.1086/261849

Bikhchandani, S.; Sharma, S. 2000. Herd behavior in financial markets, IMF Staff Papers 47: 279-310.

Borensztein, E. R.; Gelos, R. G. 2000. A panic-prome pack? The behaviour of emerging market mutual fund, Working Paper. IMF.

Choi, N.; Sias, R. 2009. Institutional industry herding, Journal of Financial Economics 94: 469491. http://dx.doi.org/10.1016/j.jfineco.2008.12.009 
Comer, G. 2006. Hybrid mutual funds and market timing performance, The Journal of Business 79: 771-797. http://dx.doi.org/10.1086/499137

De Bondt, W. F. M.; Forbes, W. P. 1999. Herding in analyst earnings forecasts: evidence from the United Kingdom, European Financial Management 5: 143-163.

http://dx.doi.org/10.1111/1468-036X.00087

Elton, E.; Gruber, M.; Blake, C. 1996. The persistence of risk-adjusted mutual fund performance, Journal of Business 69: 133-157. http://dx.doi.org/10.1086/209685

Fama, E. F.; French, K. R. 1993. Common risk factors in the returns on stocks and bonds, Journal of Financial Economics 33: 3-56. http://dx.doi.org/10.1016/0304-405X(93)90023-5

Ferruz, L.; Sarto, J. L.; Vicente, L. 2008. Herding behaviour in Spanish equity funds, Applied Economic Letters 15: 573-576. http://dx.doi.org/10.1080/13504850600706974

Frey, S.; Herbst, P.; Walter, A. 2014. Measuring mutual fund herding - a structural approach, Journal of International Financial Markets, Institutions and Money 32: 219-239.

http://dx.doi.org/10.1016/j.intfin.2014.05.006

Galariotis, E. C.; Rong, W.; Spyrou, S. I. 2015. Herding on fundamental information: a comparative study, Journal of Banking and Finance 50: 589-598.

http://dx.doi.org/10.1016/j.jbankfin.2014.03.014

Grinblatt, M.; Titman, S.; Wermers, R. 1995. Momentum investment strategies, portfolio performance, and herding: a study of mutual fund behaviour, The American Economic Review 85: $1088-1105$.

Hirshleifer, D.; Subrahmanyam, A.; Titman, S. 1994. Security analysis and trading patterns when some investors receive information before others, Journal of Finance 49: 1665-1698.

http://dx.doi.org/10.1111/j.1540-6261.1994.tb04777.x

Holmes, P.; Kallinterakis, V.; Leite Ferreira, M. P. 2013. Herding in a concentrated market: a question of intent, European Financial Management 19: 497-520.

http://dx.doi.org/10.1111/j.1468-036X.2010.00592.x

Hsieh, S. 2013. Individual and institutional herding and the impact on stock returns: evidence from Taiwan stock market, International Review of Financial Analysis 29:175-188.

http://dx.doi.org/10.1016/j.irfa.2013.01.003

Hwang, S.; Salmon, M. 2001. A new measure of herding and empirical evidence, Working Paper. City University Business School.

Ibbotson, R. G.; Kaplan, P. D. 2000. Does asset allocation policy explain 40, 90, or 100 percent of performance?, Financial Analysts Journal 56: 26-33. http://dx.doi.org/10.2469/faj.v56.n1.2327

Jones, S. L.; Lee, D.; Weis, E. 1999. Herding and feedback trading by different type of institutions and the effects on stock prices, Working Paper. The Kelley School of Business.

Lakonishok, J.; Shleifer, A.; Vishny, R. W. 1992. The impact of institutional trading on stock prices, Journal of Financial Economics 32: 23-43. http://dx.doi.org/10.1016/0304-405X(92)90023-Q OECD. 2007. Pension Markets in Focus, issue 4. OECD, Global Pension Statistics.

Oehler, A. 1998. Do mutual funds specializing in German stocks herd?, Finanzmarkt Und Portfolio Management 12: 452-465.

Scharfstein, D.; Stein, J. 1990. Herd behaviour and investment, American Economic Review 80: 465-479.

Sharpe, W. F. 1992. Asset allocation: management style and performance measurement, Journal of Portfolio Management 18: 7-19. http://dx.doi.org/10.3905/jpm.1992.409394

Sias, R. 2004. Institutional herding, Review of Financial Studies 17: 165-206. http://dx.doi.org/10.1093/rfs/hhg035

Teo, M.; Woo, S. 2004. Style effects in the cross-section of stock returns, Journal of Financial Economics 74: 367-398. http://dx.doi.org/10.1016/j.jfineco.2003.10.003 
Trueman, B. 1994. Analyst forecasts and herding behaviour, Review of Financial Studies 7: 97-124. http://dx.doi.org/10.1093/rfs/7.1.97

Voronkova, S.; Bohl, M. T. 2005. Institutional traders' behavior in an emerging stock market: empirical evidence on Polish pension fund investors, Journal of Business Finance and Accounting 32: 1537-1560. http://dx.doi.org/10.1111/j.0306-686X.2005.00639.x

Wermers, R. 1999. Mutual fund herding and the impact on stock prices, The Journal of Finance 54: 581-622. http://dx.doi.org/10.1111/0022-1082.00118

Wylie, S. 2005. Fund manager herding: a test of the accuracy of empirical results using U.K. data, The Journal of Business 78: 381-403. http://dx.doi.org/10.1086/426529

\section{APPENDIX A}

We calculate the following equation for each style $j$ to test the existence of a relationship between the previous exposures and the probability of increasing this exposure in the next period:

$$
p(t)=a+b * \hat{\beta}+\varepsilon,
$$

where $p(t)$ is the probability of increasing a specific style $j$ given the prior value of this allocation and $\hat{\beta}$ is the estimated value of the style allocation analyzed in the previous period.

The results obtained are reported in Table A.1. The table shows that the slope of the regressions is statistically different from zero for the equity and cash exposures. Therefore, the criticism of Wylie (2005) is confirmed in our dataset, and we need to calculate accurate values of $p(t)$ considering the information of the previous exposures.

In addition to Table A.1, Figures A.1-A.4 illustrate the values of the style allocation analyzed in each figure and the probability of increasing this exposure in the next period. Specifically, Figures A.1 and A.2 show a clear tendency indicating that the probability of increasing the equity exposures is inversely related to the prior value of the allocation. A finding consistent with the significant results reached in Table A.1.

Table A.1. Relationship between the probability of increasing an exposure and its previous value

\begin{tabular}{lccc}
\hline & Intercept & Slope & $\mathrm{R}^{2}$ \\
\hline$\beta_{1}$ (Equities) & 0.7654 & -0.5313 & $74.55 \%$ \\
\hline$\beta_{2}$ (Small caps) & 0.00 & 0.00 & \\
\hline$\beta_{3}$ (Fixed-income) & 0.5981 & -0.7452 & $88.21 \%$ \\
& 0.00 & 0.00 & \\
\hline$\beta_{4}$ (Cash) & 0.4454 & 0.2024 & $1.18 \%$ \\
& 0.00 & 0.43 & $7.95 \%$ \\
\hline
\end{tabular}




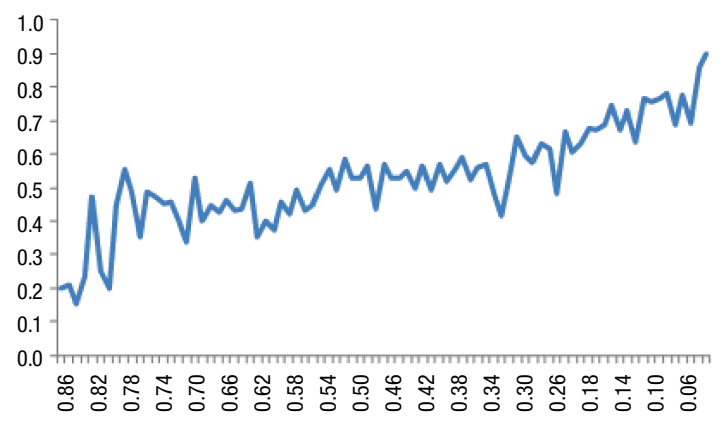

Fig. A.1. Relationship between the probability of increasing the equity exposure $\left(p(t)\right.$ values) and the previous equity weight $\left(\beta_{1}\right)$

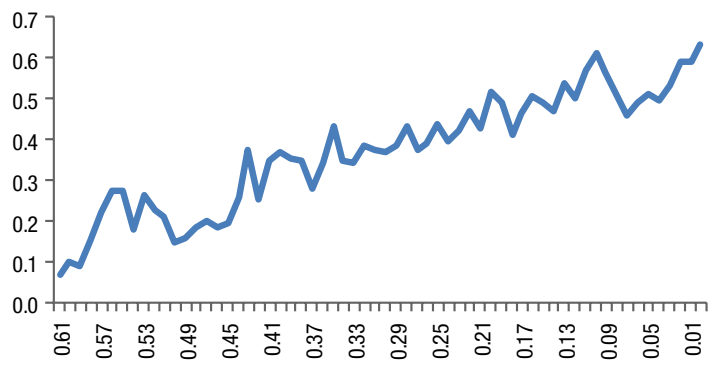

Fig. A.2. Relationship between the probability of increasing the small caps exposure $\left(p(t)\right.$ values) and the previous small cap weight $\left(\beta_{2}\right)$

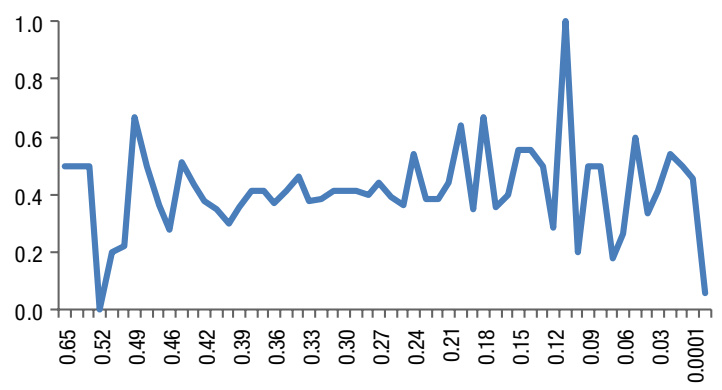

Fig. A.3. Relationship between the probability of increasing the fixed-income exposure $\left(p(t)\right.$ values) and the previous fixed-income weight $\left(\beta_{3}\right)$

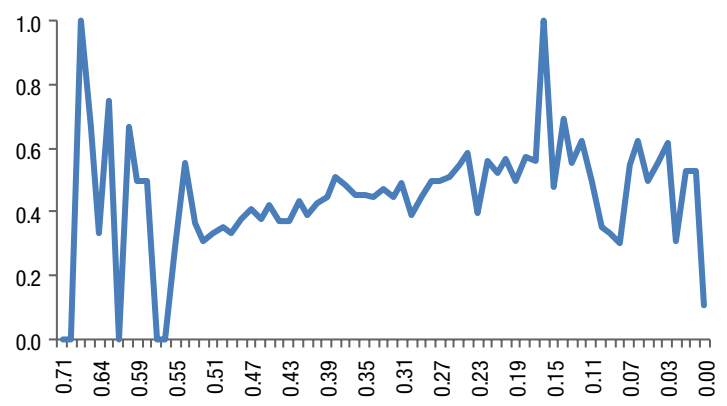

Fig. A.4. Relationship between the probability of increasing the cash exposure $\left(p(t)\right.$ values) and the previous cash weight $\left(\beta_{4}\right)$ 


\section{APPENDIX B}

We propose a non-parametric kernel regression to obtain a smooth approximation of the relationship between the probability of increasing the exposure to a certain style and the previous values of this style, which in our case is $g\left(\beta_{j}\right)$, where $j=1$ to 4 . This method only requires the set of observations of the exposures of pension plans to a certain style $j$ and the information about whether these exposures have increased or decreased in the following period. The non-parametric regression is as follows:

$$
g\left(\beta_{j}\right)=p\left[I_{t}^{p}=1 \mid \beta_{j, t-1}^{p}=\beta_{j}\right], \text { where } I_{t}^{p}=\left\{\begin{array}{l}
1 \text { if } \beta_{j, t-1}^{p}<\beta_{j, t}^{p} \\
0 \text { otherwise }
\end{array}\right.
$$

The non-parametric regression aim to determine a decreasing function of distances from a $\beta_{j}$ to calculate the weights associated with each location. The values close to that allocation receive more weight than those that are remote from it, which receive little or no weight. Given that Gaussian kernel estimators are one of the most used non-parametric methods, we calculate it as follows:

$$
\hat{g}\left(\beta_{j}\right)=\frac{\sum_{p=1}^{N} \sum_{t=t_{\min , p}+1}^{t_{\max , p}} \hat{I}_{t}^{p} K\left(\beta_{j} ; \hat{\beta}_{j, t-1}^{p}, h\right)}{\sum_{p=1}^{N} \sum_{t=t_{\min , p}+1}^{t_{\max , p}} K\left(\beta_{j} ; \hat{\beta}_{j, t-1}^{p}, h\right)}, \text { where } \hat{I}_{t}^{p}=\left\{\begin{array}{l}
1 \text { if } \hat{\beta}_{j, t-1}^{p}<\hat{\beta}_{j, t}^{p}, \\
0 \text { otherwise }
\end{array}\right.
$$

where: $K(\beta ; \mu, \sigma)$ is the value of density function of a $N(\mu, \sigma)$ distribution in the location $\beta_{j}$ and allows us to determine the weights associated to each location; $h$ is the window width; $N$ is the number of pension plans $\{p=1, \ldots, N\}$. In our case $N=193$; $t$ refers to the time period considered $\left\{1 \leq t_{\min , p}<t_{\max , p} \leq T\right\}$, being $t_{\min , p}\left(t_{\max , p}\right)$ the lower (upper) limit of the observed period of pension plan $p$. Note that each pension plan $p$ presents different life periods.

Laura ANDREU is an Assistant Professor of Finance at the Business School of the University of Zaragoza, Spain. After being visiting scholar at Centre for Finance and Investment at Exeter University (UK) and at Erasmus School of Economics (the Netherlands) she obtains her PhD in Finance from the University of Zaragoza. After her $\mathrm{PhD}$, she was also visiting scholar at the Finance Department of the University of Cologne (Germany). Her research interests include asset management and collective investment portfolios. Her research has been published in academic journals including Quantitative Finance and Journal of Financial Services Research, among others.

Cristina ORTIZ is an Assistant Professor of Finance at the Business School of the University of Zaragoza, Spain. After being visiting scholar at Glasgow Caledonian University (Glasgow, UK) and at University of Porto (Porto, Portugal) she obtains her PhD in Finance from the University of Zaragoza. After her $\mathrm{PhD}$, she was also visiting scholar at the University of Groningen (Groningen, The Netherlands). Her research interests include behavioral finance. Her research has been published in academic journals including Journal of Banking and Finance and Journal of Financial Services Research, among others.

José Luis SARTO has a PhD in Finance from the University of Zaragoza and is currently Professor of Finance at the Business School of the University of Zaragoza, Spain. He has been visiting scholar at the University of Cologne (Cologne, Germany). His primary areas of interest include portfolio management, especially mutual funds. His research has been published in academic journals including Journal of Banking and Finance and Omega: The International Journal of Management Science, among others. 